\title{
The Mode of Action of CY216 and CY222 in Plasma
}

Citation for published version (APA):

Beguin, S., Wielders, S., Lormeau, J. C., \& Hemker, H. C. (1992). The Mode of Action of CY216 and

CY222 in Plasma. Thrombosis and Haemostasis, 67(1), 33-41. https://doi.org/10.1055/s-0038-1648375

Document status and date:

Published: 01/01/1992

DOI:

10.1055/s-0038-1648375

Document Version:

Publisher's PDF, also known as Version of record

\section{Please check the document version of this publication:}

- A submitted manuscript is the version of the article upon submission and before peer-review. There can be important differences between the submitted version and the official published version of record.

People interested in the research are advised to contact the author for the final version of the publication, or visit the DOI to the publisher's website.

- The final author version and the galley proof are versions of the publication after peer review.

- The final published version features the final layout of the paper including the volume, issue and page numbers.

Link to publication

\footnotetext{
General rights rights.

- You may freely distribute the URL identifying the publication in the public portal. please follow below link for the End User Agreement:

www.umlib.nl/taverne-license

Take down policy

If you believe that this document breaches copyright please contact us at:

repository@maastrichtuniversity.nl

providing details and we will investigate your claim.
}

Copyright and moral rights for the publications made accessible in the public portal are retained by the authors and/or other copyright owners and it is a condition of accessing publications that users recognise and abide by the legal requirements associated with these

- Users may download and print one copy of any publication from the public portal for the purpose of private study or research.

- You may not further distribute the material or use it for any profit-making activity or commercial gain

If the publication is distributed under the terms of Article $25 \mathrm{fa}$ of the Dutch Copyright Act, indicated by the "Taverne" license above, 


\title{
The Mode of Action of CY216 and CY222 in Plasma
}

\author{
Suzette Béguin, Simone Wielders, J. C. Lormeau*, and H. Coenraad Hemker \\ From the Department of Biochemistry and Cardiovascular Research Institute, University of Limburg, \\ Maastricht, The Netherlands and *Sanofi Recherche, Gentilly, France
}

\section{Summary}

Three fractions of the low molecular weight heparin CY216 (fraxiparin, mean molecular weight [MMW] 5,090), with MMWs of respectively, 3,090, 4,400 and 7,910 were prepared by gel permeation chromatography. From CY222 (MMW 3,770) as well as from CY216 and its three fractions the material with high affinity to antithrombin III (AT III) was obtained by chromatography on immobilised AT III. The molecular weight distribution of each of the ten preparations thus obtained was determined by high performance liquid chromatography, while the content of AT III binding material was determined by stoichiometric titration of AT III, monitored by intrinsic fluorescence enhancement.

We measured the effect of all heparins on the decay of endogenous thrombin in plasma and on the overall generation of thrombin in plasma, triggered via the extrinsic or via the intrinsic pathway. From these data we calculated the time course of prothrombin conversion, i. e. the course of factor Xa activity as expressed by prothrombinase activity.

It was found that in platelet-poor plasma the anticoagulant properties of the heparins are largely dependent on their antithrombin action, which is determined by their content of high affinity material with a MW of 5,400 or higher. The specific antithrombin activity of all heparins, when expressed in terms of material with high affinity to antithrombin III (HAM) with a MW $>5,400$ is $13.0 \mathrm{~min}^{-1} /(\mu \mathrm{g} / \mathrm{ml}$ ) (range $10.5-15.9)$. The anticoagulant potency is not influenced by the presence of low-affinity material and hardly by material with $\mathrm{MW}<5,400$.

In platelet-rich plasma, however, the presence of non-AT III binding material enhances the inhibition, presumably by neutralising heparin binding material originating from activated platelets. The ultra low MW fractions $(<3,400)$ show a similar activity in PPP and in PRP.

\section{Introduction}

Unfractionated heparin (UFH), in concentrations that almost completely block the appearance of free thrombin triggered via the intrinsic pathway in platelet-poor plasma (PPP) $(\sim 0.1 \mathrm{U} / \mathrm{ml})$, acts primarily by enhancing the disappearance of thrombin, rather than by inhibiting prothrombin activation $(1,2)$. In pathways where factor VIII figures, the feedback activation of this factor by thrombin is a rate limiting step $(2,3)$. There, the anti-thrombin activity of UFH will inhibit the generation of prothrombin converting activity indirectly by retarding factor VIII activation. In platelet-rich plasma (PRP) up to $0.4 \mathrm{U} / \mathrm{ml}$ of UFH can be neutralized by platelet factor $4(\mathrm{pf} 4)$ released from activated platelets (4). Consequently it is not unrealistic to assume that in situations where activated platelets are present even concentrations of UFH higher than $0.1 \mathrm{U} / \mathrm{ml}$ will still act via thrombin

Correspondence to: Dr. S. Béguin, University of Limburg, Dept. of Biochemistry, P.O.B. 616, 6200 MD Maastricht, The Netherlands inactivation rather than via inhibition of prothrombin conversion. Conversely, the synthetic pentasaccharide (PS) that represents the antithrombin III (AT III) binding site of heparin, acts on free factor $\mathrm{Xa}$ and is not or hardly affected by pf4 $(5,6)$. This substance is therefore essentially different from UFH in that it blocks the generation of thrombin but does not enhance its breakdown. Heparin with a chainlength of $<18$ monosaccharide units have previously been reported to have similar properties (7). We have proposed to call those heparins which, like UFH, exert their action mainly via thrombin inactivation $S$-type heparins and heparins that act primarily on factor Xa, like PS, P-type heparins (1). To our surprise most low molecular weight heparins (LMWH) acted like S-type- rather than like P-type heparins, despite the fact that their mean molecular weights suggest that they should contain considerable amounts of P-type material.

In the present study we attempt to define what fractions of CY216 and CY222 contain the main active material. To this end we prepared three fractions of CY216 with medium, low and ultra low mean molecular weights. From these fractions as well as from CY216 and CY222 the heparin with high affinity to AT III was isolated by affinity chromatography. The ten fractions thus obtained were characterised in terms of molecular weight distribution by HPLC and in terms of content of high affinity AT III binding material (HAM) by titration of a known amount of AT III with the heparin, monitored by the enhancement of the intrinsic fluorescence of the protein. We measured their effect in PPP on the decay of endogenous thrombin and on thrombin generation via the extrinsic and the intrinsic pathway. The effect on prothrombin conversion velocity was calculated from these data. The effect of the heparins on thrombin generation in PRP has been assessed, so as to get an impression of their susceptibility to neutralisation by activated platelets.

It will be shown that the overall inhibitory activity on thrombin generation of a heparin in PPP is mainly determined by its content of HAM with a MW $>5,400$. In PRP the heparin material with no affinity for AT III but high affinity for the heparin neutralising activity (pf4) from the platelets, protects the HAM fraction from neutralisation.

\section{Materials and Methods}

\section{Materials}

The chromogenic substrate for thrombin was H.D-Phe-Pip-Arg-pNA (S2238) from KABI, Sweden. Kaolin was "Kaolin léger" provided by B.L.B. Laboratoires du Bois de Boulogne (Puteaux, France). The low molecular weight heparins CY216 (4 batches) and CY222 ( 2 batches) were supplied and fractionated by Sanofi Recherche, Centre Choay (Paris, France). One batch of CY216 was separated into a medium (M), low (L) and ultra low (U) molecular weight fractions by gel permeation chromatography on agarose acrylamide gel ACA 202 (IBF, France). From the two heparin preparations, as well as from the three fractions, the material with high affinity to antithrombin III (HAM) was obtained by affinity chromatography on a sepharose column with covalently bound AT III. The 4th International Heparin Standard (4th I.S. H.) was 
obtained from the National Institute for Biological Standards and Control and the synthetic pentasaccharide that represents the AT III binding site of heparin (PS) (5) was supplied by Sanofi Recherche, Centre Choay (Paris, France). Phospholipids were $20 \%$ phosphatidyl serine and $80 \%$ phosphatidyl choline prepared as in ref. 8.

\section{Plasma}

Blood from healthy donors was collected into $0.13 \mathrm{M}$ trisodium citrate; nine parts of blood to one part of citrate solution. A first centrifugation was performed at $130 \times \mathrm{g}$, at $15^{\circ} \mathrm{C}$ for $15 \mathrm{~min}$, and platelet rich plasma (PRP) was taken from the supernatant. A second centrifugation was done for $15 \mathrm{~min}$ at $15^{\circ} \mathrm{C}$ and $2,000 \times \mathrm{g}$ to obtain PPP. The platelet count of the PRP was adjusted to $300,000 \mathrm{pl} / \mu \mathrm{l}$ by dilution with PPP from the same donor. Pooled PPP was prepared from at least 10 donors and the third centrifugation was done at $4^{\circ} \mathrm{C}$, for $1 \mathrm{~h}$ at $20,000 \times \mathrm{g}$, this plasma was stored at $-80^{\circ} \mathrm{C}$. It was checked that the clotting factors and the antiproteases were within the normal range (9). Defibrinated plasma was obtained by mixing an aliquot of plasma with $1: 50$ volume of a reptilase solution, letting a clot form for $5 \mathrm{~min}$ at $37^{\circ} \mathrm{C}$ and keeping the clotted plasma at $0^{\circ} \mathrm{C}$ for $10 \mathrm{~min}$. The fibrin formed was discarded by centrifugation $\left(10 \mathrm{~min}, 2,000 \times \mathrm{g}, 4^{\circ} \mathrm{C}\right)$ or by winding it on a small plastic spatula. The concentrations of factors II, VII, VIII, IX, X, XI and XII did not significantly change by the reptilase treatment (9).

\section{Proteins}

Reptilase was obtained from Laboratories Stago (Asnières, France) and a solution was made according to the instructions of the manufacturer. Soybean trypsin inhibitor (batch No. 43 F-800) was obtained from Sigma (St. Louis, USA). Staphylocoagulase was obtained from Laboratoires Stago (Asnières, France) and prepared according to the instructions of the manufacturer. Human brain thromboplastin was prepared according to Owren and Aas (10).

\section{Determination of Molecular Weight Distribution}

The molecular weight distribution profiles of the heparins and the different fractions were determined by gel permeation HPLC on a G2000 SW column $(7.5 \times 300 \mathrm{~mm})$ obtained from LKB (Paris, France) connected to a HPLC apparatus composed of a Waters 510 pump, a Waters 484 UV detector and a VAC 2000 Calcul station. The column was calibrated with a series of narrow-sized heparin fragments prepared by deaminative cleavage followed by gel filtration. The MWs of these standards were calculated from their precise oligosaccharide composition as determined by ${ }^{13} \mathrm{C}$ NMR.

\section{Determination of Thrombin Generation in Plasma}

To $240 \mu \mathrm{l}$ of defibrinated plasma was added $60 \mu \mathrm{l}$ of $0.05 \mathrm{M}$ Tris- $\mathrm{HCl}$, $0.1 \mathrm{M} \mathrm{NaCl}, 0.5 \mathrm{mg} / \mathrm{ml}$ ovalbumin, pH 7.35 , containing heparin at the desired concentration. Thrombin formation was started by the addition of $60 \mu \mathrm{l}$ of a solution containing $100 \mathrm{mM}$ of $\mathrm{CaCl}_{2}$ and a trigger of coagulation. For the extrinsic system this was human brain thromboplastin, diluted so as to clot the inhibited, non-defibrinated reaction mixture in $70 \mathrm{~s}$ (final dilution $1: 240$ ). For the intrinsic system $1 \mu \mathrm{M}$ phospholipid and $0.025 \mathrm{mg}$ kaolin (final concentrations) were used. At intervals, a $10 \mu \mathrm{l}$ aliquot of the mixture was sampled into a disposable plastic cuvette containing $0.465 \mathrm{ml}$ of $0.05 \mathrm{M}$ Tris- $\mathrm{HCl}, 0.1 \mathrm{M} \mathrm{NaCl}, 20 \mathrm{mM}$ EDTA, $0.5 \mathrm{mg}$ ovalbumin $/ \mathrm{ml}$, pH 7.90 and $25 \mu \mathrm{l}$ of $\mathrm{S} 2238(4 \mathrm{mM})$ prewarmed for at least $5 \mathrm{~min}$ at $37^{\circ} \mathrm{C}$. After about $120 \mathrm{~s}$ the reaction in the cuvette was stopped by adding $300 \mu 1$ of concentrated acetic acid. The precise moments of sampling and stopping were recorded on a personal computer by means of pushbutton equipped pipettes. The cuvettes were read at $405 \mathrm{~nm}$ in a double wavelength $(405-500 \mathrm{~nm})$ dedicated instrument prepared in our workshop, reading on the same computer. Amidolytic activities $(\mathrm{mOD} / \mathrm{min})$ were automatically calculated from the optical density and the starting and stopping timcs. The observed amidolytic activity is the sum of thrombin activity and the activity of $\alpha_{2}$ macroglobulin bound thrombin $\left(\alpha_{2} \mathrm{M}-\mathrm{T}\right)$. Thus at the end of the reaction a stable level of activity is obtained, due to the $\alpha_{2} \mathrm{M}-\mathrm{T}$ complex formed. Assuming a pseudo-first order reaction between thrombin and $\alpha_{2}$ macroglobulin, which is likely because of the large excess in plasma of this inhibitor over thrombin, one can calculate the course of free thrombin if $k_{2}$, the pseudofirst order constant of this reaction is known. Using the method of ref. $8 \mathrm{k}_{2}$ was found to be $0.21 \mathrm{~min}^{-1}$, independent of the heparin concentration. The check for the validity of the procedure and of the numerical value of $k_{2}$ was the obtaining of a zero stable end level of the calculated concentration of free thrombin. Thrombin generation in PRP was determined essentially in the same way as in PPP, except that thrombin generation was triggered with $1: 6$ volume of human brain thromboplastin diluted 1:400 with $0.1 \mathrm{M} \mathrm{CaCl}_{2}$.

\section{Calculation of the Velocity of Prothrombin Conversion}

The time course of the velocity of prothrombin conversion was calculated from the amidolytic activity curve with the aid of a computer program as described previously (9). Briefly, the thrombin activity, calculated as indicated above, was used to obtain at each moment of sampling $(t)$, the amount of thrombin present $\left(T_{t}\right)$ and the velocity $\left(v_{t}\right)$ of thrombin generation: $v_{t}=\left(T_{t+1}-T_{t}\right) / l$, where $l=$ the time lapse between $t+1$ and $t$. The breakdown velocity $b$, can be calculated from the AT III dependent breakdown constant $\left(k_{1}\right)$ and the amount of thrombin available $(T)$. The velocity of prothrombin conversion $\left(p_{t}\right)$ equals the velocity of thrombin generation $\left(v_{t}\right)$ plus the breakdown velocity $\left(b_{t}\right): p_{t}=v_{t}+b_{t}$. All inhibitions are expressed in $\%$ of non-inhibited plasma run in parallel. The validity of the calculation was checked by also measuring the disappearance of prothrombin during thrombin generation directly with the aid of staphylocoagulase as described in ref. 2. For each of the heparins tested this was done at at least one concentration in the neighbourhood of $\mathrm{IC}_{50}$ for the thrombin peak. No significant differences were found between the inhibitions calculated on basis of the thrombin generation curves and those measured directly.

\section{The Pseudo First Order Rate Constant of Thrombin Inhibition in Plasma}

Defibrinated plasma $(120 \mu \mathrm{l})$ was incubated with $14 \mu \mathrm{l}$ of buffer containing $0.05 \mathrm{M}$ Tris- $\mathrm{HCl}, 0.1 \mathrm{M} \mathrm{NaCl}, 0.5 \mathrm{mg}$ ovalbumin $/ \mathrm{ml}, \mathrm{pH} 7.35$. Thrombin generation was started as described in the previous section. Two minutes after the peak activity of thrombin, $6 \mu \mathrm{l}$ of Soybean Trypsin Inhibitor (SBTI) solution $(10 \mathrm{mg} / \mathrm{ml})$ was added. together with $10 \mu \mathrm{l}$ of buffer that contained the heparin to be tested. SBTI at this concentration was shown to block the activity of prothrombinase completely and instantaneously and not to influence the activity of thrombin (9). At suitable time intervals $(2-10 \mathrm{~s})$ after addition of the SBTT solution, $10 \mu \mathrm{l}$ aliquots of the incubation mixture were added to cuvettes to measure residual thrombin activity as described. The pseudo first order rate constant of inhibition of thrombin generated in plasma was calculated by

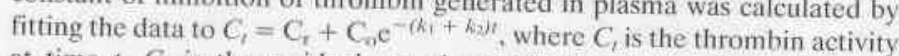
at time $t, C_{\mathrm{r}}$ is the residual, steady end-level activity, $C_{\mathrm{o}}+C_{\mathrm{r}}$ is the thrombin activity at the time of SBTI addition, $k_{\mathrm{I}}$ is the AT III-dependent decay constant of inhibition of thrombin, $k_{2}$ is the decay constant of inhibition of thrombin by $\alpha_{2}-\mathrm{M}$ as described before (9).

The second order rate constants were obtained from the slope of the plot of the pseudo-first order rate constants against the heparin concentra-
tion.

\section{Antithrombin III Binding}

The interaction between AT III and heparin was investigated by fluorescence measurements (11). These measurements were performed at room temperature on a SLM Aminco SPF- $500 \mathrm{C}$ spectrofluorometer. The change in the fluorescence of AT III during titration with heparin was measured at excitation and emission wavelengths of $285 \mathrm{~nm}$ and $345 \mathrm{~nm}$. The molar concentrations of the heparin species with high affinity for AT III in each fraction were determined by stoichiometric titration of AT III concentration $(1 \mu \mathrm{M})$ in $2 \mathrm{ml} 0.05 \mathrm{M}$ TRIS and $0.1 \mathrm{M} \mathrm{NaCl}(\mathrm{pH}$ 7.5) buffer. The result was a linear increase in the fluorescence of AT III at increasing heparin concentrations, until a plateau value was reached at the equivalence point. The value of \%HAM was calculated from the AT III binding normality and the mean molecular weight. The AT III concentration was determined by titration of the AT III with active site titrated factor $\mathrm{Xa}(12)$. 


\section{Results}

\section{Molecular Weight Distributions and Antithrombin III Binding}

Fig. 1 shows the HPLC chromatograms of the heparins used. It is interesting to note that the molecular weight distribution of the high affinity fractions of CY222 and CY216, when compared to the total material, had shifted to higher values. Table 1 gives the weight average- and peak molecular weights obtained from these chromatograms. Table 1 also gives the results of the fluorescence experiments in terms of percentage of HAM. There is a general trend for the percentage of HAM to decrease with the molecular weight. For the HAM fractions we also determined the percentage of material at or above the critical chain length of 18 sugar units that allows an action on thrombin (ACLM) (13-20). On basis of the ACLM content we can divide the heparins in two groups, those whose HAM contains a significant amount of higher MW material (group 1) and those whose HAM contains only traces of ACLM (group 2). Only the molecules that have both a high affinity to AT III and a sufficient length can effectively catalyse thrombin inhibition. We calculated the \% of such material in each fraction by multiplying the \% ACLM and the $\%$ HAM of the heparin. Because of the differences in molecular weight distribution between the heparins and their high affinity fractions, the \% ACLM values of the high affinity fractions were also applied to the heparin from which the HAM material had been obtained.

\section{Decay of Endogenous Thrombin in Plasma}

We found that for all the LMWHs there exists a linear relationship between the concentration of heparin added to plasma and the pseudo-first order decay constant of endogenous thrombin (Fig. 2). This linearity holds over the entire concentration range studied. We define the specific antithrombin activity of a heparin as the increase in the pseudo first order rate constant of endogenous thrombin decay per $\mu \mathrm{g} / \mathrm{ml}$ of material. This value is obtained from the slope of lines such as those in Fig. 2. From the specific antithrombin activities of the heparins and their HAM percentages, we calculated the specific activities of the HAM contained in the preparations (Table 1 ). From this table it can be seen that, expressed in this way, the specific activity of a heparin preparation and of the high affinity fraction prepared from it are not significantly different. There appears to be a clearcut difference between group 1 and group 2 heparins in that the former have, on the average, a tenfold higher specific activity when expressed in terms of HAM.

We also calculated the specific activity per amount of HAM with a molecular weight $>5,400$, i. e. above the critical chain length for interaction with thrombin (ACL-HAM). In this way we obtained the specific activity per $\mu \mathrm{g} / \mathrm{ml}$ of material with a $\mathrm{MW}$ $>5,400$ that binds to heparin. Expressed in this way the differences between the different heparins in group 1 tend to vanish and the specific activities scatter around a mean of $13.0 \mathrm{~min}^{-1} /$ $(\mu \mathrm{g} / \mathrm{ml})$, without systematic variation with MW. Unfractionated heparin still has a roughly two times higher specific activity. Even when expressed in terms of ACL-HAM, the materials of group 2 do not attain the specific antithrombin activity of those of group 1. The low amount of ACLM in the heparins of the second group implies a large experimental error, so we doubt the significance of this finding.

\section{Thrombin Generation in Platelet Poor Plasma}

The generation of thrombin, measured as amidolytic activity but compensating for the activity of $\alpha_{2}$-macroglobulin bound thrombin, in the absence and presence of different concentrations of heparins has been determined in the extrinsic and intrinsic systems. The influence of representative batches of CY216 and CY222 is shown in Fig. 3. In the extrinsic system there is no significant lag phase in the presence of either heparin. In the
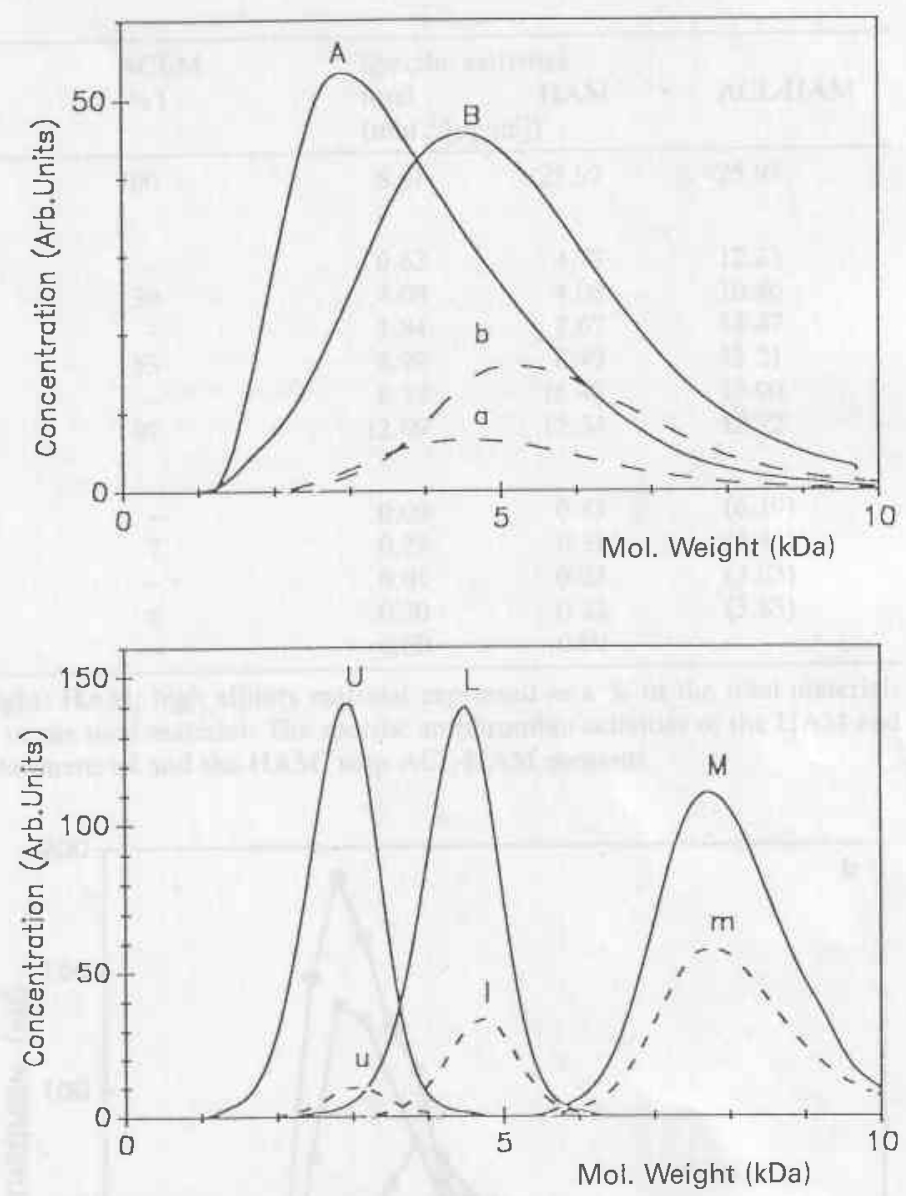

Fig. 1 The molecular weight distribution of the heparins studied. Upper frame: CY222 (Aa) and CY216 (Bb); lower frame: the medium (Mm)-, low (L1)- and ultra low (Uu) fractions from CY216. Drawn lines: total material; dashed lines: high affinity fractions

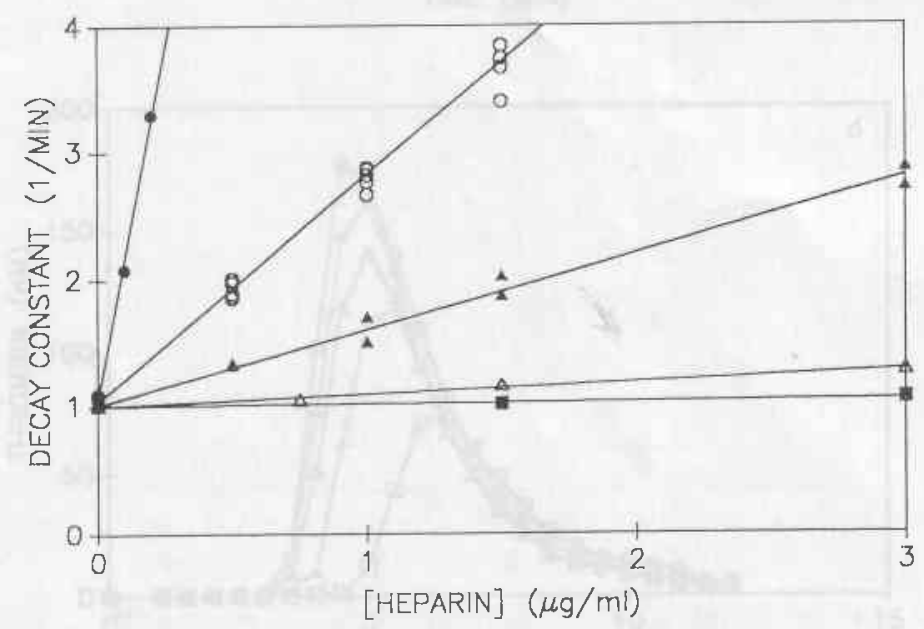

Fig. 2 The pseudo-first order decay constant of endogenous thrombin in platelet poor plasma. In order of steepness of the curves: $\triangle$ CY216, medium MW fraction; O CY216, total material (4 batches); $\Delta$ CY222, total material ( 2 batches); $\triangle$ CY216, low MW fraction; CY216, ultralow MW fraction 
intrinsic system, on the contrary, there is a dose dependent lag phase for both heparins, albeit less marked with CY222 than with CY216. From these curves we calculated the concentration of heparin that would cause $25 \%$ inhibition of the thrombin peak (IC25). The IC25 value was chosen, rather than the conventional
IC50, because the latter value, for practical reasons, can usually not be obtained for prothrombinase inhibition; it is often so high that it causes an inhibition of the thrombin peak of more than $85 \%$. This causes thrombin concentrations to be so low as not to allow sufficiently accurate calculation of prothrombinase activity.

Table 1 Molecular properties and specific antithrombin activities

\begin{tabular}{|c|c|c|c|c|c|c|c|}
\hline Prep. & $\begin{array}{l}\text { MMW } \\
\text { (kDa) }\end{array}$ & $\begin{array}{l}\text { PMW } \\
(\mathrm{kDa})\end{array}$ & $\begin{array}{l}\text { HAM } \\
(\%)\end{array}$ & $\begin{array}{l}\text { ACLM } \\
(\%)\end{array}$ & $\begin{array}{l}\text { Specif } \\
\text { total } \\
\left(\min ^{-1}\right.\end{array}$ & $\begin{array}{l}\text { ties } \\
\text { HAM }\end{array}$ & ACL-HAM \\
\hline UFH & 14.50 & - & 33 & 100 & 8.57 & 25.97 & 25.97 \\
\hline Group 1 & & & & & & & \\
\hline CY222 & 3.77 & 2.9 & 13 & - & 0.62 & 4.77 & 12.23 \\
\hline CY222-H & 5.12 & 4.5 & 100 & 39 & 4.08 & 4.08 & 10.46 \\
\hline CY216 & 5.09 & 4.5 & 24 & - & 1.84 & 7.67 & 14.47 \\
\hline CY216-HA & 5.41 & 5.15 & 74 & 53 & 4.79 & 6.49 & 12.21 \\
\hline CY216M & 7.91 & 7.6 & 54 & 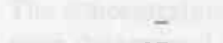 & 8.33 & 15.43 & 15.90 \\
\hline CY216M-HA & 7.74 & 7.7 & 98 & $x^{2}=$ & 12.09 & 12.34 & 12.72 \\
\hline Group 2 & & & & & & & \\
\hline CY216L & 4.40 & 4.5 & 21 & - & 0.09 & 0.43 & $(6.19)$ \\
\hline CY216L-HA & 4.62 & 4.65 & 92 & 7 & 0.29 & 0.31 & $(4.44)$ \\
\hline CY216U & 3.09 & 2.9 & 6 & - & 0.01 & 0.23 & (3.83) \\
\hline CY216U-HA & 3.40 & 3.0 & 88 & 6 & 0.20 & 0.23 & $(3.83)$ \\
\hline PENTA & 1.70 & 1.7 & 100 & - & 0.00 & 0.00 & - \\
\hline
\end{tabular}

MMW: weight average mean molecular weight; PMW: peak molecular weight; HAM: high affinity material expressed as a \% of the total material; ACLM: above critical chain length $(\mathrm{MW}>5,400)$ material expressed as a \% of the total material. The specific antithrombin activities of the HAM and the ACL-HAM fractions were calculated from the specific activity of the total material and the HAM, resp ACL-HAM contents.
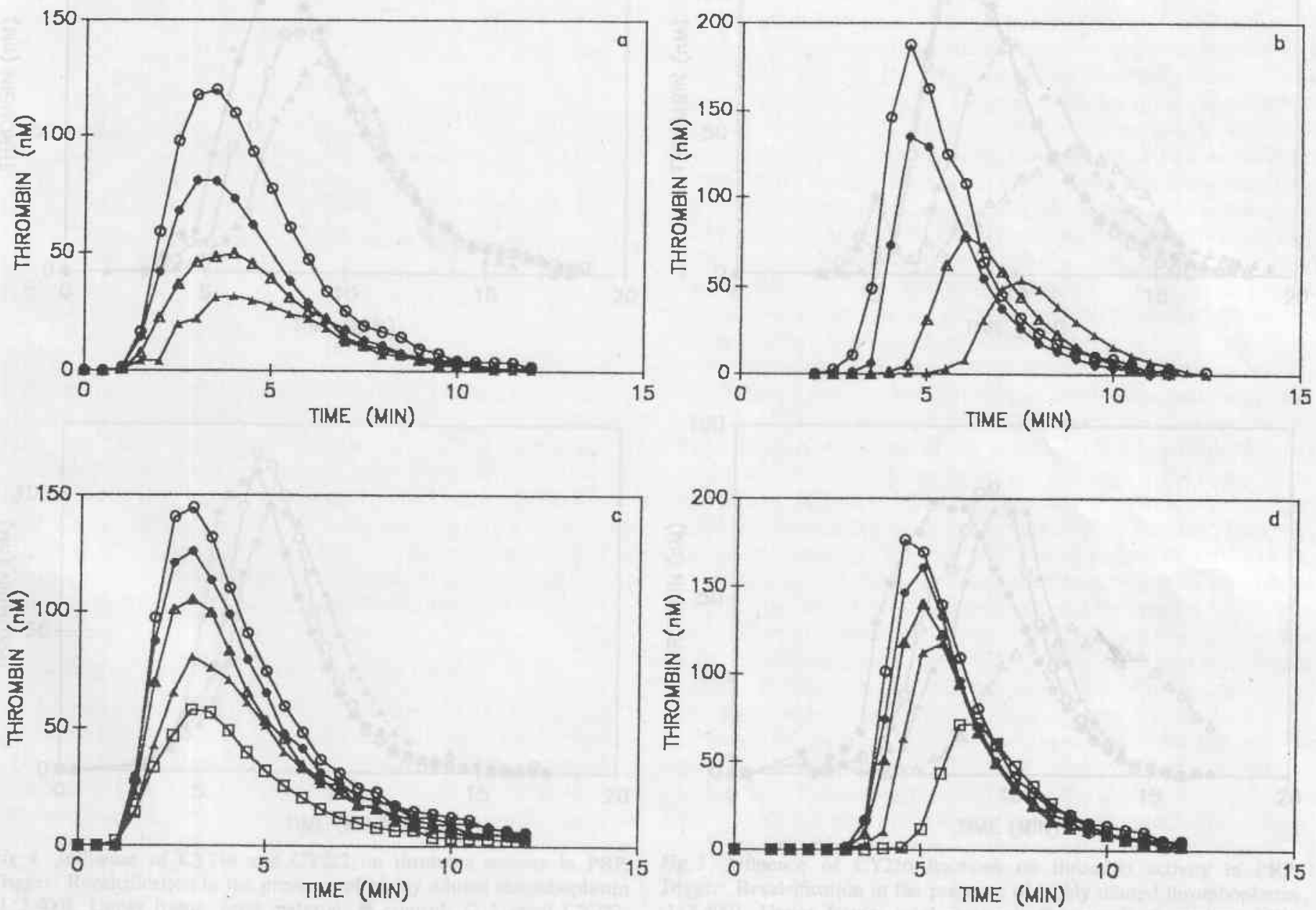

Fig, 3 The influence of CY216 and CY222 on thrombin generation in platelet poor plasma. Upper frames: CY216; lower frames CY222; Left frames: extrinsic system; right frames: intrinsic system. CY216 concentrations in order of peak height: control, $0.5 \mu \mathrm{g} / \mathrm{ml} ; 1.0 \mu \mathrm{g} / \mathrm{ml} ; 1.5 \mu \mathrm{g} / \mathrm{ml}$. CY222 concentrations in order of peak height: control; $0.5 \mu \mathrm{g} / \mathrm{ml} ; 1.0 \mu \mathrm{g} / \mathrm{ml} ; 1.5 \mu \mathrm{g} / \mathrm{ml} ; 3 \mu \mathrm{g} / \mathrm{ml}$ 
Table 2 IC25 (in $\mu \mathrm{g} / \mathrm{ml}$ ) for thrombin peak inhibition

\begin{tabular}{llllll}
\hline Prep. & \multicolumn{6}{l}{$\begin{array}{l}\text { IC25 } \\
\text { extr. }\end{array}$} & intr. & mean & HAM & ACL-HAM \\
& 0.10 & 0.07 & - & 0.03 & 0.030 \\
\hline UFH & 1.35 & 1.38 & 1.36 & 0.18 & 0.069 \\
CY222 & 0.22 & 0.17 & 0.20 & 0.20 & 0.078 \\
CY222-HA & 0.36 & 0.36 & 0.36 & 0.09 & 0.046 \\
CY216 & 0.21 & 0.17 & 0.19 & 0.14 & 0.075 \\
CY216-HA & 0.11 & 0.10 & 0.10 & 0.05 & 0.052 \\
CY216M & 0.09 & 0.05 & 0.07 & 0.07 & 0.068 \\
CY216M-HA & 3.06 & 2.38 & 2.72 & 0.57 & $(0.040)$ \\
CY216L & 0.64 & 0.72 & 0.68 & 0.63 & $(0.044)$ \\
CY216L-HA & 8.62 & 7.46 & 8.08 & 0.49 & $(0.029)$ \\
CY216U & 0.85 & 0.94 & 0.90 & 0.79 & $(0.047)$ \\
CY216U-HA & 0.40 & 0.40 & 0.40 & 0.40 & - \\
PENTA & & &
\end{tabular}

The concentrations at which $25 \%$ the thrombin peak was inhibited were determined in the total material. From the known HAM, resp. ACLHAM contents it was calculated what concentrations of HAM and ACLHAM these concentrations of total material represent
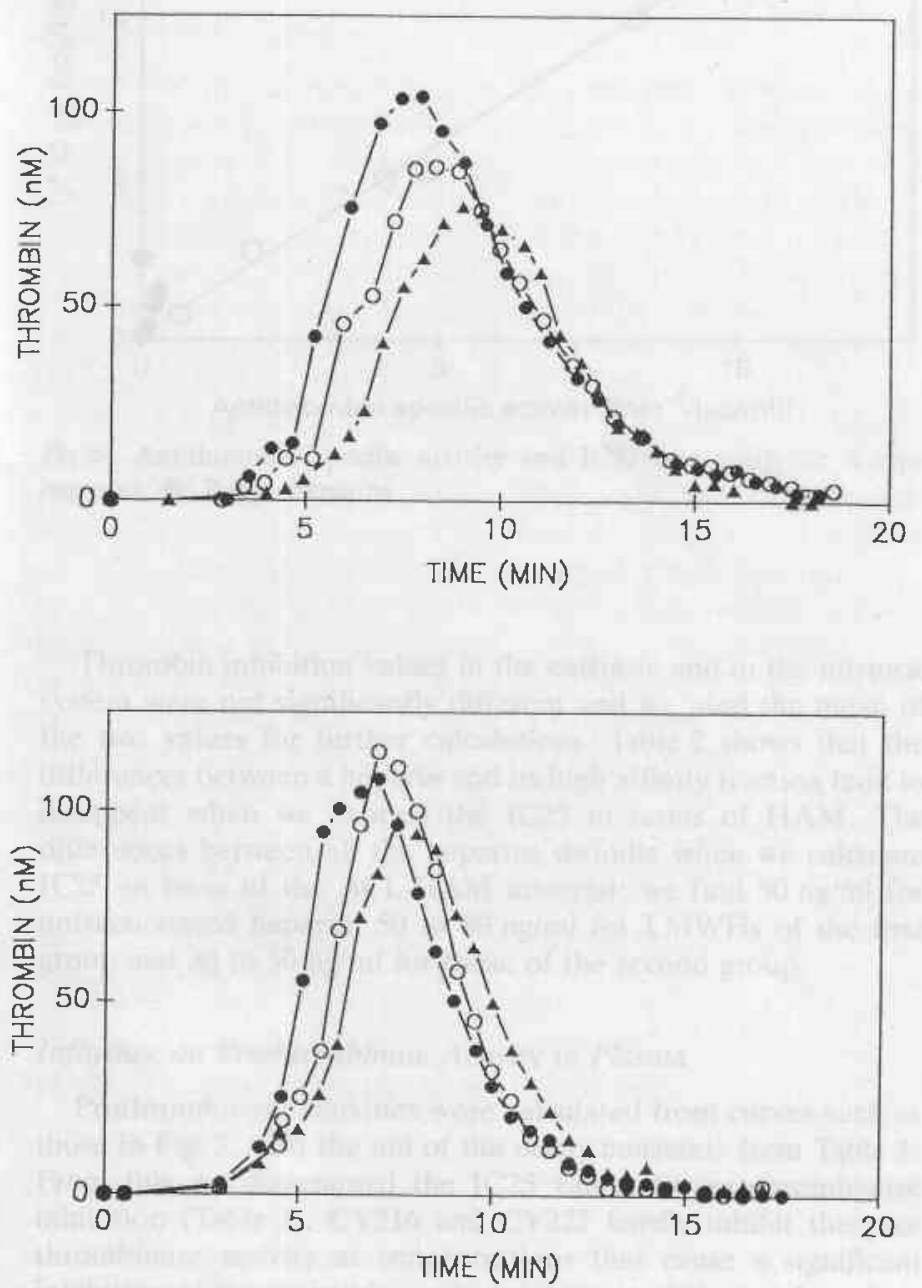

Fig. 4 Influence of CY216 and CY222 on thrombin activity in PRP. Trigger: Recalcification in the presence of highly diluted thromboplastin $(1: 2,400)$. Upper frame: total material; control; $03 \mu \mathrm{g} / \mathrm{ml}$ CY222;

A $1 \mu \mathrm{g} / \mathrm{ml}$ CY216. Lower frame: high affinity fractions; control; $0.45 \mu \mathrm{g} / \mathrm{ml} \mathrm{CY} 222 ; \Delta 0.5 \mu \mathrm{g} / \mathrm{ml}$ CY216
Table 3 IC25 (in $\mu \mathrm{g} / \mathrm{ml}$ ) of prothrombinase, extrinsic and intrinsic systems

\begin{tabular}{lllll}
\hline \multirow{2}{*}{ Prep. } & \multicolumn{2}{l}{$\begin{array}{l}\text { Extrinsic } \\
\text { total }\end{array}$} & HAM & \multicolumn{2}{c}{ Intrinsic system } \\
& total & HAM \\
\hline UFH & 0.45 & 0.15 & 0.26 & 0.09 \\
CY222 & 5.54 & 0.72 & 3.32 & 0.43 \\
CY222-HA & 0.61 & 0.61 & 0.36 & 0.36 \\
CY216 & 1.45 & 0.35 & 1.30 & 0.31 \\
CY216-HA & 1.00 & 0.74 & 0.38 & 0.28 \\
CY216M & 0.82 & 0.44 & 0.23 & 0.13 \\
CY216M-HA & 0.27 & 0.27 & 0.12 & 0.12 \\
CY216L & 3.85 & 0.81 & 2.94 & 0.62 \\
CY216-HA & 0.75 & 0.69 & 0.81 & 0.74 \\
CY216U & 8.93 & 0.54 & 7.94 & 0.48 \\
CY216U-HA & 1.09 & 0.96 & 1.32 & 1.16 \\
PENTA & 0.40 & 0.40 & 0.40 & 0.40 \\
\hline
\end{tabular}

The concentrations at which $25 \%$ the prothrombinase peak was inhibited were determined in the total material. From the known HAM content it was calculated what concentrations of HAM material these concentrations of total material represent
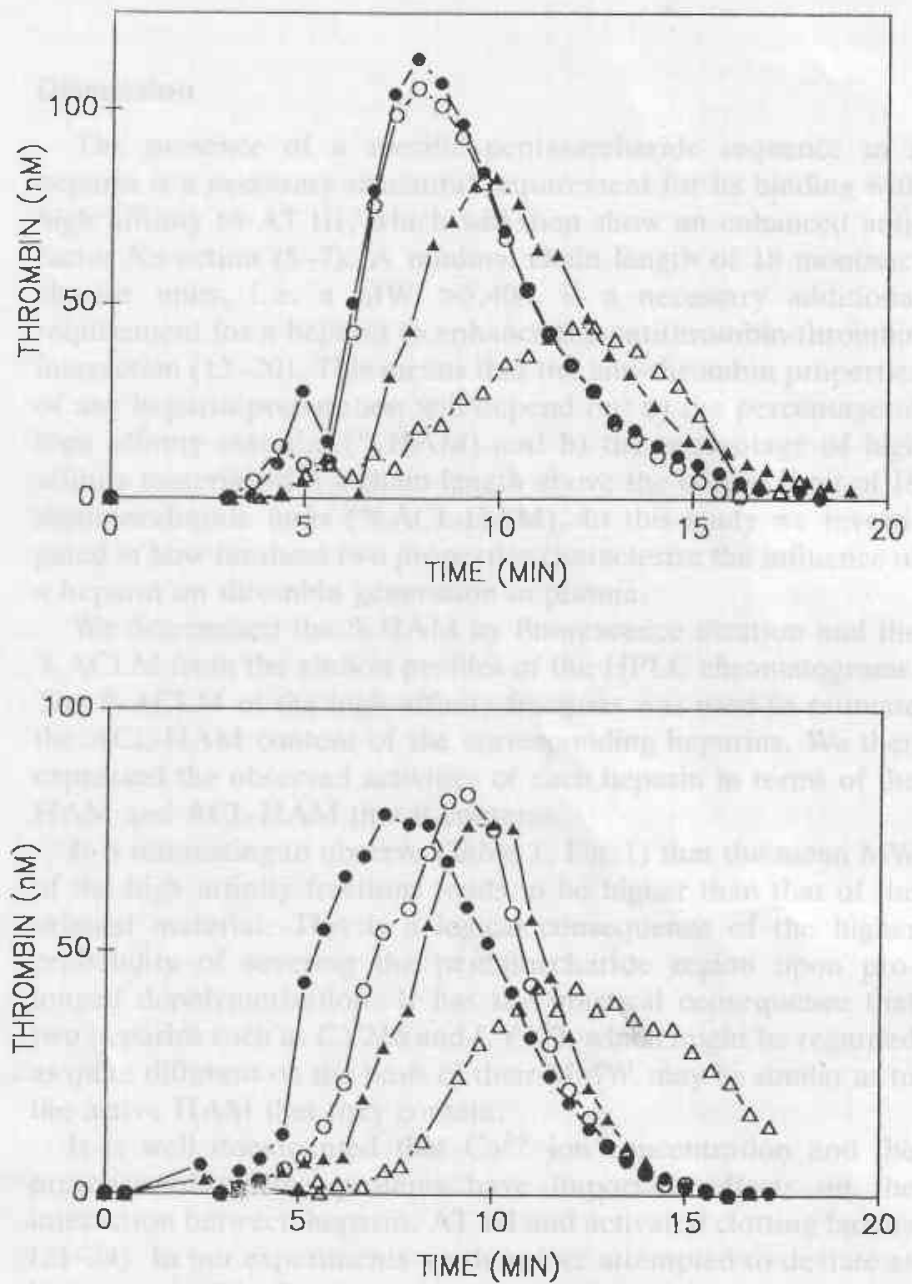

Fig. 5 Influence of CY216 fractions on thrombin activity in PRP. Trigger: Recalcification in the presence of highly diluted thromboplastin $(1: 2,400)$. Upper frame: total material; control: 0 medium MW, $0.2 \mu \mathrm{g} / \mathrm{ml} ; \Delta$ low MW, $6 \mu \mathrm{g} / \mathrm{ml} ; \Delta$ ultralow MW, $20 \mu \mathrm{g} / \mathrm{ml}$. Lower frame: high affinity material: control; 0 medium MW, $0.15 \mu \mathrm{g} / \mathrm{ml}$; low MW, $1.5 \mu \mathrm{g} / \mathrm{ml} ; \triangle$ ultralow $\mathrm{MW}, 2 \mu \mathrm{g} / \mathrm{ml}$ 
Table 4 Inhibition of the peak of thrombin generation in platelet-rich plasma

\begin{tabular}{lclc}
\hline Prep. & $\begin{array}{l}\text { Conc. } \\
(\mu \mathrm{g} / \mathrm{ml})\end{array}$ & \multicolumn{2}{l}{ Inhibition $(\%)$} \\
\hline UFH & 0.20 & 55 & 0 \\
CY222 & 3.00 & 55 & 16 \\
CY222-HA & 0.45 & 52 & 0 \\
CY216 & 1.00 & 56 & 27 \\
CY216-HA & 0.50 & 54 & 9 \\
CY216M & 0.20 & 45 & 6 \\
CY216M-HA & 0.15 & 46 & 0 \\
CY216L & 6.00 & 49 & 22 \\
CY216L-HA & 1.50 & 52 & 2 \\
CY216U & 20.00 & 57 & 54 \\
CY216U-HA & 2.00 & 55 & 51 \\
PENTA & 1.00 & 49 & 53 \\
\hline ConcEntratins & & & \\
\hline
\end{tabular}

Concentrations of heparin where sought that inhibit thrombin formation in PPP approx. 50\%, then the effect of that concentration on thrombin generation in PRP was assessed.

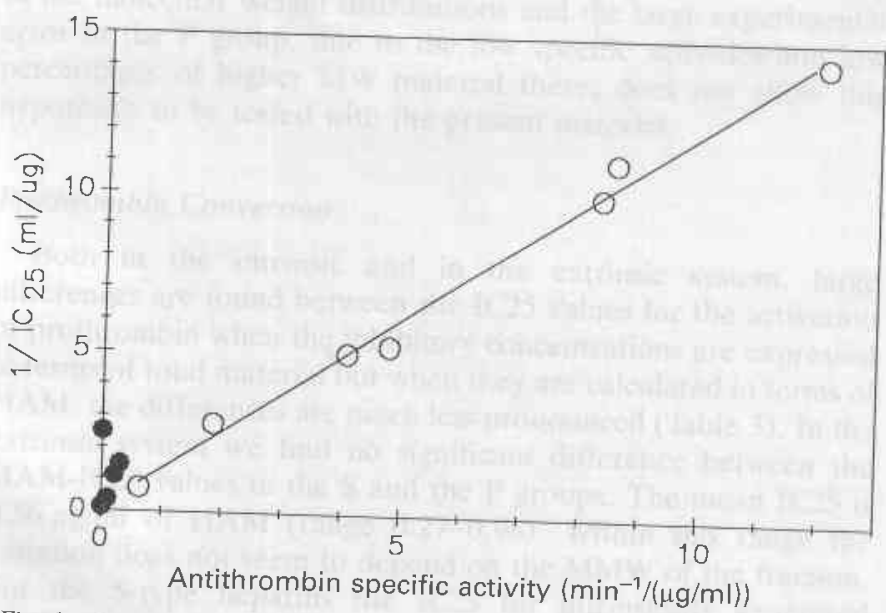
Fig. 6 Antithrombin specific activity and IC25 (see text); O: $S$ type
heparins; : P type heparins

Thrombin inhibition values in the extrinsic and in the intrinsic system were not significantly different and we used the mean of the two values for further calculations. Table 2 shows that the differences between a heparin and its high affinity fraction tend to disappear when we express the IC25 in terms of HAM. The differences between all the heparins dwindle when we calculate IC25 on basis of the ACL_HAM material; we find $30 \mathrm{ng} / \mathrm{ml}$ for unfractionated heparin, 50 to $80 \mathrm{ng} / \mathrm{ml}$ for LMWHs of the first group and 30 to $50 \mathrm{ng} / \mathrm{ml}$ for those of the second group.

\section{Influence on Prothrombinase Activity in Plasma}

Prothrombinase activities were calculated from curves such as those in Fig. 3, with the aid of the decay constants from Table 1. From this we determined the IC25 values for prothrombinase inhibition (Table 3). CY216 and CY222 hardly inhibit the prothrombinase activity at concentrations that cause a significant inhibition of the thrombin peak. Inhibitions of the prothrombinase activity in the intrinsic system were found to be roughly twice as important as those in the extrinsic system for heparins of the first group (mean ratio of the activities 2.1 , range $1.1-3.6$, no systematic variation with $\mathrm{MMW}$ ). For the heparins of the second group there was no difference between the inhibitions in the instrinsic and the extrinsic system (mean ratio 1.0 , range $0.8-1.3$ )
(Table 3 ).

The heparins of the first group, especially in the extrinsic system, show a low inhibition of the prothrombinase activity as compared to the thrombin peak inhibition. This is best reflected in the ratio of the IC25 for prothrombinase to that for thrombin, which is 5.4 (range $3.0-8.8$ ). In the second group this ratio is 1.22
(range $1.42-1.10$ ).

\section{Influence on Thrombin Generation in Platelet Rich Plasma}

The influence of platelets on the inhibitory capacity of the different heparins was investigated (Figs. 4 and 5). We determined the inhibition in PRP caused by a concentration of heparin that inhibits $\sim 50 \%$ in PPP. At IC 50 -PPP, unfractionated heparin is completely neutralised by activated platelets (4). The same is seen for all high affinity fractions except the ultra low molecular weight material (Table 4).

If the low-affinity material is present, CY222, CY216 and the low molecular weight fraction of CY216 retain a significant capacity to inhibit the thrombin peak in PRP. The medium molecular weight fraction behaves like UFH in that it has a poor activity in PRP. The ultra low fractions and the pentasaccharide do not seem to be influenced by the presence of platelets. They show practically equal activity in PPP and PRP.

\section{Discussion}

The presence of a specific pentasaccharide sequence in a heparin is a necessary structural requirement for its binding with high affinity to AT III, which will then show an enhanced antifactor Xa action (5-7). A minimal chain length of 18 monosaccharide units, i.e. a $\mathrm{MW}>5,400$, is a necessary additional requirement for a heparin to enhance the antithrombin-thrombin interaction $(13-20)$. This means that the anti-thrombin properties of any heparin preparation will depend on: a) the percentage of high affinity material (\%HAM) and b) the percentage of high affinity material with a chain length above the critical limit of 18 monosaccharide units (\% ACL-HAM). In this study we investigated in how far these two properties characterize the influence of a heparin on thrombin generation in plasma.

We determined the \%HAM by fluorescence titration and the $\%$ ACLM from the elution profiles of the HPLC chromatograms. The \% ACLM of the high affinity fractions was used to estimate the ACL-HAM content of the corresponding heparins. We then expressed the observed activities of each heparin in terms of the HAM and ACL-HAM that it contains.

It is interesting to observe (Table 1, Fig. 1) that the mean MW of the high affinity fractions tends to be higher than that of the original material. This is a logical consequence of the higher probability of severing the pentasaccharide region upon prolonged depolymerisation. It has the practical consequence that two heparins such as CY216 and CY222, which might be regarded as quite different on the basis of their MMW, may be similar as to the active HAM that they contain.

It is well documented that $\mathrm{Ca}^{2+}$ ion concentration and the presence of plasma proteins have important effects on the interaction between heparin, AT III and activated clotting factors $(21-24)$. In our experiments we therefore attempted to deviate as little as possible from the in vivo conditions by working in a plasma milieu and at normal $\mathrm{Ca}^{2+}$ concentrations. We measured thrombin generation in PPP and PRP and determined the influence of the heparins on thrombin breakdown. From these data we calculated the effect of the heparins on prothrombin 


\section{Thrombin Breakdown}

From Table 1 it is immediately obvious that the heparins come in two kinds: those with a high specific activity in thrombin decay and those with a low one. This is especially clear when the specific activity is expressed in terms of high affinity material. The first group, that of the S heparins (1), comprises CY216, its medium molecular weight fraction and CY222. To the second group, the P heparins, belong to the low and ultra-low molecular weight fractions of CY216. The specific decay constant, when calculated per $\mu \mathrm{g}$ of HAM, does not differ significantly between a heparin and its corresponding high affinity fraction, indicating that the low affinity material present does not influence the thrombin decay. Calculated per $\mu \mathrm{g}$ of ACL-HAM, the specific activity does not vary much between the LMWHs of the S-type group (mean 13.0, range 10.7-15.9). For the P-type LMWHs, the small amount of ACLM, which is necessarily just above the lower limit that allows antithrombin activity, seems to have a low specific activity, whereas that of UFH seems to be some 2 times higher than that of the LMWHs. This is suggestive of variation of the molar antithrombin specific activity with the chain length. The dispersity of the molecular weight distributions and the large experimental error in the $\mathrm{P}$ group, due to the low specific activities and low percentages of higher MW material there, does not allow this hypothesis to be tested with the present material.

\section{Prothrombin Conversion}

Both in the intrinsic and in the extrinsic system, large differences are found between the IC25 values for the activation of prothrombin when the inhibitory concentrations are expressed in terms of total material but when they are calculated in terms of HAM, the differences are much less pronounced (Table 3). In the extrinsic system we find no significant difference between the HAM-IC25 values in the $\mathrm{S}$ and the Proups. The mean IC25 is $0.56 \mu \mathrm{g} / \mathrm{ml}$ of HAM (range $0.27-0.96$ ). Within this range the variation does not seem to depend on the MMW of the fraction. For the S-type heparins the IC25 for intrinsically generated prothrombinase is about two times lower than for extrinsic prothrombinase (mean 0.26 , range $0.12-0.43$ ). This is not found for the P-type group (mean 0.75 , range $0.48-1.16$ ). This difference is probably explained by the fact that, in the intrinsic system, those heparins that have a significant antithrombin activity inhibit the generation of prothrombinase indirectly by inhibiting the thrombin mediated factor VIII activation, which may entail factor IXa inhibition $(1,2,25-27)$. In situations where inhibition of thrombin mediated feedback, although present, is not rate limiting, i. e. for all heparins in the extrinsic system and for the Ptype heparins in the intrinsic system, the HAM-IC25 of prothrombinase is similar. This indicates that all LMWHs have roughly the same antiprothrombinase effect unless their capacity to inhibit thrombin causes secondary inhibitory effects on the generation of prothrombinase activities.

\section{Inhibition of Free Thrombin Formed in Plasma}

The HAM-IC25 values for thrombin inhibition in the S-type group show a mean of $0.12 \mu \mathrm{g} / \mathrm{ml}$ (range $0.05-0.20$ ), which is about 5 times lower than those for prothrombinase. This shows that the antithrombin activity of the S-type heparins overshadows their antiprothrombinase activity. In the P-type group the HAMIC25 for thrombin (mean $0.62 \mu \mathrm{g} / \mathrm{ml}$, range $0.49-0.79$ ) is not different from that of prothrombinase inhibition $(0.75 \mu \mathrm{g} / \mathrm{ml}$, range $0.54-0.96$ ), which is a normal consequence of the fact that, in the absence of anti-thrombin activity, the inhibition of the thrombin peak results from inhibition of prothrombinase activity.
Fig. 6 shows that the inhibitory potency of the S-type heparins, expressed as the inverse of their IC25 for thrombin, is directly proportional to their specific anti-thrombin activity. Antithrombin activity results in immediate, proportional inhibition of the thrombin peak, whereas the anti-factor Xa activity does not.

This apparent paradox is readily explained from the nature of the prothrombin converting enzyme. The levels of thrombin obtained in clotting plasma result from the combined action of heparin on prothrombin conversion and on thrombin decay.

An increase in antithrombin activity under the influence of heparin will lead to a proportional decrease in the thrombin concentration. A decrease in the prothrombinase activity will cause a proportional decrease in prothrombin conversion. But prothrombinase activity is not proportional to the amount of factor Xa present, so that factor Xa inactivation does not lead to a proportional decrease in prothrombinase activity.

Prothrombinase is a tripartite complex of factors $\mathrm{Xa}$ and $\mathrm{Va}$ and phospholipid arising from simple chemical equilibria (28). From Béguin (2) we know that the normal peak prothrombinase

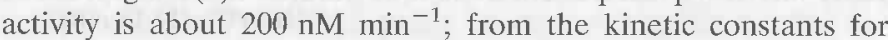
prothrombin conversion given by Rosing et al. (8), we calculate that under the conditions of our experiments this reaction velocity is obtained by $0.3 \mathrm{nM}$ or less of prothrombinase complex, i.e. at slightly more than $0.3 \mathrm{nM}$ of the rate limiting prothrombinase component. Pieters and Lindhout (29) found that in clotting plasma, under our conditions, factor $\mathrm{Va}$ is the limiting prothrombinase component and that factor $\mathrm{Xa}$ is in large excess $(\sim 10 \mathrm{nM})$ over the limiting factor $\mathrm{Va}(\sim 0.3 \mathrm{nM})(29)$. The binding constant of factor Xa to phospholipid bound factor $\mathrm{Va}$ is $0.1 \mathrm{nM}(30)$. This means that at $0.3 \mathrm{nM}$ factor $\mathrm{Va}$ and $10 \mathrm{nM}$ factor $\mathrm{Xa}, \sim 0.297 \mathrm{nM}$ prothrombinase is formed while $1 \mathrm{nM}$ factor Xa leads to the formation of $\sim 0.273 \mathrm{nM}$ prothrombinase. Inhibition of the factor $\mathrm{Xa}$ peak of $\sim 90 \%$ will cause $\sim 8 \%$ inhibition of prothrombinase.

As early as 1970 Yin proposed that it was a normal consequence of the clotting cascade that factor $\mathrm{Xa}$ inhibition would lead as readily to inhibition of thrombin generation as inhibition of thrombin would (31). This idea is at the basis of much of the later work on the antithrombotic action of heparins. Now that we know the details of the enzymology of prothrombinase it is readily seen why this is not true. It has been suggested previously that tests based on the inhibition of prothrombin activation and/or on the catalysis of thrombin inhibition provide a useful basis for assigning in vivo potency to both unfractionated and LMW heparins (32). Our results suggest that thrombin inhibition rather than prothrombin conversion should be the yardstick for the potency of heparins.

In terms of ACL-HAM the IC25 value for thrombin inhibition is very similar for all S-type heparins: $64 \mathrm{ng} / \mathrm{ml}$ (range 46-78). For unfractionated heparin it is even lower: $30 \mathrm{ng} / \mathrm{ml}$, which suggests that, as was seen with the thrombin decay constants, UFH is about 2 times more active than LMWHs.

The inhibition of thrombin generation in clotting plasma by LMWHs is thus brought about by their antithrombin activity as soon as they possess that activity. At a $M W<5,400$, having anti $\mathrm{Xa}$ activity only, heparins will still inhibit thrombin formation in plasma, but at about 5 fold higher concentrations. This explains why the amount of HAM with a MW $<5,400$ in a LMWH preparation has to be fairly high before it starts to act via inhibition of prothrombin conversion (33). If we assume that a decrease of the amount of free thrombin arising in activated plasma is the lever of the antithrombotic action of heparins (and probably of many other drugs), then it also explains why the synthetic pentasaccharide and other P-heparins need to be given in high doses in order to have an antithrombotic effect (34). It is clear that a LMW heparin cannot be regarded as a homogeneous 
substance. Its different components have different in vitro activities and will in all probability also have different pharmacokinetic properties, the lower MW molecules having a longer half life time. This makes that the effect observed in vivo after injection may progressively shift from the S-type to the P-type.

\section{Platelet Rich Plasma}

In platelet rich plasma the inhibition by LMWHs is systematically more important than that brought about by an amount of UFH which is equivalent in PPP (4). This must be attributed to the fact that much more pf 4 binding molecules are present in a dose of LMWH than in an otherwise equivalent dose of UFH, so that LMWH preparations can neutralize the pf4 released by the activated platelets of PRP $(35,36$, cf also the accompanying paper by Schoen et al.).

The experiments reported in Figs. 4 and 5 and in Table 4 show that the LMWHs retain an inhibitory activity in the presence of platelets under conditions where an amount of UFH, which in PPP is equipotent, does not. This is evidently a function of the non-AT III binding material present, because the effect is systematically less important in the HAM preparations than in the corresponding original fractions. There is also an effect of MW. On the one hand the medium MW preparation is neutralised fairly efficiently, while on the other hand the ultralow MW heparins escape neutralisation almost entirely, even if they contain a high $\%$ of HAM.

Since we may consider PRP to be a better model of the situation in vivo than PPP is, this suggests that the clinical efficacy of a LMWH may be determined, at least in part, by the amount of its material that reacts with pf4 but not with AT III on the one hand, and by the amount that binds to AT III but not so well to pf 4 on the other. The former will neutralise pf 4 and in this way protect anticoagulant heparin. The latter will be to a certain degree immune to pf4 action.

\section{Conclusions}

Our observations lead to the following hypothesis:

The most active part of LMWHs is to be found in the AT III binding fraction with a molecular weight higher than 5,400. The effect of these fractions on the biochemical processes in blood coagulation is not essentially different from that of UFH, but their pharmacodynamics are more favourable and they are less readily neutralised by (products from) activated platelets.

It follows from this hypothesis that it should be worthwile to investigate, in animal and human studies, the antithrombotic effect of a LMWH compared to its high affinity $>5,400 \mathrm{MW}$ fraction, spiked with different amounts of inactive, but platelet factor 4 binding material.

Besides the AT III affinity and the length of more than 18 sugar units, other properties of heparin may determine its activity. Anti-factor $\mathrm{Xa}$ and antithrombin activity have been reported to increase gradually with $\mathrm{MW}$ and it is not inconceivable that chemical composition outside the pentasaccharide region may modify the properties of a heparin. The present data however do not allow conclusions on this matter.

\section{Acknowledgements}

We would like to thank the "Broeders van de Beyaert" for their generous donations of normal plasma. We are grateful to Dr Theo Lindhout for critically reading and discussing the manuscript.

\section{REFERENCES}

1. Hemker HC. The mode of action of heparin in plasma. In: Thrombosis and Haemostasis. Verstraete M, Vermylen M, Lijnen J, Arnout HR (eds). Int Soc Thromb Haemostas and Leuven University Press, Leuven 1987, pp 17-36.

2. Béguin $\mathrm{S}$, Lindhout $\mathrm{T}$, Hemker HC. The mode of action of heparin in plasma. Thromb Haemostas 1988; 60: 457-62.

3. Pieters J, Lindhout T, Hemker HC. In situ generated thrombin is the only enzyme that effectively activates factor VIII and factor $\mathrm{V}$ in plasma. Blood 1989; 74: 1021-4.

4. Béguin S, Lindhout T, Hemker HC. The effect of trace amounts of tissue factor on thrombin generation in platelet rich plasma its inhibition by heparin. Thromb Haemostas 1989; 61: 25-9.

5. Choay J, Petitou M, Lormeau JC, Synaï P, Casu B, Gatti G. Structure activity relationship in heparin: A synthetic pentasaccharide with high affinity for antithrombin III and eliciting high anti-factor Xa activity. Biochem Biophys Res Commun 1983; 116: 492-9.

6. Béguin S, Choay J, Hemker HC. The action of a synthetic pentasaccharide on thrombin generation in whole plasma. Thromb Haemostas 1989; 61 (3): 379-401.

7. Thomas DP, Merton RE, Barrowcliffe TW, Thunberg L, Lindahl U. Effects of heparin oligosaccharides with high affinity for Antithrombin III in experimental venous thrombosis. Thromb Haemostas 1982; 47 (3): $244-8$.

8. Rosing J, Tans G, Govers-Riemslag JWP, Zwaal RAF, Hemker HC. The role of phospholipid and factor $\mathrm{Va}$ in the prothrombinase complex. J Biol Chem 1980; 249: 7798-807.

9. Hemker HC, Willems GM, Béguin S. A computer assisted method to obtain the prothrombin activation velocity in whole plasma independent of thrombin decay processes. Thromb Haemostas 1986; 56: 9-17.

10. Owren $\mathbf{P}$, Aas $K$. The control of dicumarol therapy and the quantitative determination of prothrombin and proconvertin. Scand J Clin Lab Invest 1951; 3: 201-18.

11. Nordeman B, Björk I. Binding of low-affinity and high-affinity heparin to antithrombin. Ultraviolet difference spectroscopy and circular dichroism studies. Biochemistry 1987; 17: 3339-44.

12. Smith RL. Titration of activated bovine factor X. J Biol Chem 1973; 248: 2418-23.

13. Lane DA, Denton J, Flynn AM, Thunberg L, Lindahl U. Anticoagulant activities of heparin oligosaccharides and their neutralization by platelet factor 4. Biochem J 1984; 218: 725-32.

14. Denton J, Lane DA, Thunberg L, Slater AM, Lindahl U. Binding of platelet factor 4 to heparin oligosaccharides. Biochem J 1983; 209: $455-60$.

15. Thunberg L, Lindahl U. On the molecular-weight-dependence of the anticoagulant activity of heparin. Biochem J 1979; 181: 241-3.

16. Andersson LO, Barrowcliffe TW, Holmer E, Johnson EA, Södenström G. Molecular weight dependency of the heparin potentiated inhibition of thrombin and activated factor X. Effect of heparin neutralization in plasma. Thromb Res 1979; 15: 531-41.

17. Barrowcliffe TW, Merton RE, Havercroft SJ, Thunberg L, Lindhal U, Thomas DP. Anticoagulant activities of heparin oligosaccharides. Thromb Res 1984; 34: 125-33.

18. Hoylaerts M, Owen WG, Collen D. Involvement of heparin chain length in the heparin-catalyzed inhibition of thrombin by antithrombin III. J Biol Chem 1984; 259: 5670-7.

19. Ellis V, Scully MF, Kakkar VV. The relative molecular mass dependence of the anti-factor Xa properties of heparin. Biochem $\mathrm{J}$ 1986; 238: 329-33.

20. Danielson A, Raub E, Lindahl U, Björk I. Role of ternary complexes, in which heparin binds both antithrombin and proteinase, in the acceleration of the reactions between antithrombin and thrombin or factor Xa. J Biol Chem 1986; 261: 15467-73.

21. Jesty J. Analysis of the generation and inhibition of activated coagulation factor $\mathrm{X}$ in pure systems and in human plasma. J Biol Chem 1986; 261: 8695-702.

22. Jesty $\mathbf{J}$. The kinetics of inhibition of $\alpha$-thrombin in human plasma, $\mathbf{J}$ Biol Chem 1986; 261: 10313-8.

23. Barrowcliffe TW, Shirley-Le Y. The effect of calcium chloride on anti$\mathrm{Xa}$ activity of heparin and its molecular weight fractions. Thromb Haemostas 1989; 62 (3): 950-4. 
24. O'Neall-Speight M, Griffith M.J. Calcium inhibits the heparin-catalyzed antithrombin III/thrombin reaction by decreasing the apparent binding affinity of heparin for thrombin. Arch Biochem Biophys 1983; 225 (2): 958-63.

25. Ofosu FA, Sie P, Modi GJ, Fernandez F, Buchanan MR, Blajchman MA, Boneu B, Hirsh $\mathbf{J}$. The inhibition of thrombin-dependent positive feedback reactions is critical to the expression of the anticoagulant effect of heparin. Biochem J 1987; 243: 579-88.

26. Béguin S., Dol F, Hemker HC. Secondary effect of antithrombin property of unfractionated heparin: Factor IXa inhibition in the intrinsic pathway. Br J Haematol 1990; 76 (Suppl 1): 24.

27. Béguin S, Dol F, Hemker HC. Factor IXa inhibition contributes to the heparin effect. Thromb Haemostas 1991; 66: 306-9.

28. Hemker HC, Esnouf MP, Hemker PW, Swart ACW, Macfarlane RG. Formation of prothrombin converting activity. Nature 1968; 215 : $246-51$.

29. Pieters J, Lindhout T. The limited importance of factor Xa inhibition to the anticoagulant property of heparin in thromboplastin-activated plasma. Blood 1988; 72: 2048-52.

30. Lindhout T, Govers-Riemslag JWP, Waart-van-de P, Hemker HC, Rosing J, Factor Va-Factor Xa interaction. Effects of phospholipid vesicles of varying composition. Biochemistry 1982; 21: 5494-502.
31. Yin ET, Wessler S, Stoll PJ. Biological properties of the naturally occurring inhibitor to activated factor X. J Biol Chem 1971; 246: 3703-11.

32. Ofosu FA, Smith LM, Anvari N, Blajchman MA. An approach to assigning in vitro potency to unfractionated and low molecular weight heparins based on the inhibition of prothrombin activation and catalysis of thrombin inhibition. Thromb Haemostas 1988; 60: 193-8.

33. Béguin S, Mardiguian J, Lindhout T, Hemker HC. The mode of action of low molecular weight heparin preparation (PK 10169) and two of its major components on thrombin generation in plasma. Thromb Haemostas 1989; 61: 30-4.

34. Walenga JM, Bara L, Petitou M, Fareed J, Samama M, Choay J. The inhibition of the generation of thrombin and the antithrombotic effect of a pentasaccharide with sole anti-factor Xa activity. Thromb Res 1988; 51: 23-33.

35. Loscalzo J, Melnick B, Handin RI. The interaction of platelet four and glycosaminoglycans. Arch Biochem Biophys 1985; 240: 446-55.

36. Walz DA, Hung GL. In vivo studies on the binding of heparin and its fraction with platelet factor 4 . Semin Thromb Hemostas 1984; 11 (1): $40-7$.

Received November 30, 1990 Accepted after revision July 1, 1991 